\title{
A exploração sexual de crianças e adolescentes no contexto de grandes eventos: a Copa do Mundo no Brasil 2014
}

Sexual exploitation of children and adolescents in the context of major events: the World Cup in Brazil 2014

\section{Elisangela Aparecida Machado da Silva}

Pesquisadora de pós-doutorado no Programa de Pós-graduação em Transportes (PPGT) da Universidade de Brasília - UnB, Brasília/DF, Brasil

E-mail: elisangela-machado@hotmail.com

\section{Anna Flora Werneck}

Consultora estratégica de proteção de crianças e adolescentes durante grandes eventos esportivos da Childhood Brasil - São Paulo/SP, Brasil

E-mail: annaflora@childhood.org.br

\section{Thomaz Kauark Chianca}

Doutor em Avaliação Interdisciplinar pela Universidade de Western Michigan - UM, Ann Arbor/MI, Estados Unidos da América

E-mail: thomaz.chianca@gmail.com

\section{Benedito Rodrigues dos Santos}

Pesquisador associado do International Institute for Child Rights and Development (IICRD) da Universidade de Victoria - UVic, Victoria/BC, Canadá

E-mail: benedito.santos.br@gmail.com 


\section{RESUMO}

O discurso comum entre especialistas e sociedade civil é sobre o aumento dos registros das violações de direitos contra crianças e adolescentes em contextos de grandes eventos mundiais, nomeadamente a exploração sexual. A metodologia proposta para a pesquisa buscou identificar evidências da exploração sexual e tomou como case a Copa do Mundo de Futebol 2014, no Brasil, a partir da sistematização de dados secundários (2012 a 2014). Os principais resultados gerados foram a oportunidade de ter as informações dos registros organizados em uma única base de dados e analisados de forma a se identificar a interferência do grande evento. Nos resultados encontrados, conclui-se que os tipos de violações registrados cotidianamente, e que ocorrem no âmbito intrafamiliar e comunitário, se repetiram durante o período do grande evento, com aumento dos registros de violência sexual, marcados pela invisibilidade da exploração sexual. Na perspectiva da gestão, esta pesquisa produziu dados e evidências que podem auxiliar os organizadores de eventos dessa natureza a definirem estratégias concretas para a prevenção de violações de direitos. Na perspectiva científica, esta pesquisa é uma referência metodológica para futuros estudos quantiqualitativos e para investigações que trabalhem a correlação entre responsabilidade social dos destinos turísticos e a garantia de direitos das crianças e adolescentes em contexto de grandes eventos.

Palavras-chave: Brasil. Exploração Sexual. Turismo. Grandes Eventos.

\section{ABSTRACT}

The common discourse between experts and civil society is about the increasing violations of children records and adolescents in situations of major world events, especially sexual exploitation. The methodology proposed for the research sought to identify evidence on sexual exploitation, took as a case the 2014 Football World Cup in Brazil and counted on the systematization of secondary data (2012 to 2014). The main results generated from the research were the opportunity to have the information of the records organized in single database and analyzed in order to identify the interference of the large events. From the results found, the types of violations recorded on a daily basis, occurring within the family and community, repeated during the period of the great event, with increased records of sexual violence, with marked invisibility of sexual exploitation. From the perspective of management, the research produced data and evidence that can help the organizers of events of this nature to define concrete strategies to prevent these violations. In the scientific perspective, the research consists of a reference methodology for future quantitativequalitative studies, and research on the correlation between social responsibility of tourist destinations and the guarantee of the rights of children and adolescents in the context of major events.

Keywords: Brazil. Sexual Exploitation. Tourism. Major Events. 


\section{INTRODUÇÃO}

Prontamente, relacionam-se eventos a algo como comemoração, festa ou diversão. É comum, no meio acadêmico, associá-los ao entretenimento. Os eventos, independente de sua natureza e propósito, são meios de entretenimento (Melo Neto, 2001), ideia que liga sua produção à atividade de lazer. Atualmente, os eventos têm mais a oferecer do que momentos de lazer e descontração, pois são também considerados um arranjo de atividades econômicas, serviços e estruturas, com interações que movimentam a atividade turística dos destinos.

É, portanto, intrínseca a relação entre eventos e turismo, já que reflete diretamente na dinâmica dos lugares. A realização de eventos gera no imaginário coletivo da sociedade receptora, sobretudo quando relacionado aos grandes eventos esportivos de futebol, a expectativa de canalização de investimentos, promoção da imagem dos destinos, incremento de capitais, de infraestrutura e de movimentação de turistas.

Contraditoriamente, em meio a euforia da realização dos grandes eventos, há indícios de que estes podem aumentar a exposição de crianças e adolescentes aos diferentes tipos de violações de direitos, além de agravar suas condições socioeconômicas. Brackenridge, Palmer-Felgate, Rhind, Hills, Kay, Tiivas, Faulkner, e Lindsay (2013), no estudo Riscos e recomendações para a proteção à infância em grandes eventos esportivos, identificaram a necessidade de investimentos em ferramentas sólidas de monitoramento e avaliação das intervenções para a proteção à infância. Em complemento, no estudo empírico Let's Win This Game Together - Documenting violations of children's rights around the 2014 FIFA World Cup in Brazil (Blerk \& Rizzini, 2015) foram identificados cinco tipos de violações de direitos: violência policial (e do Exército), remoções, exploração sexual, trabalho infantil e negligência.

No geral, os resultados dos estudos apontam para um aumento nos riscos de exploração sexual de crianças e adolescentes durante grandes eventos esportivos, mas, ainda assim, não existem dados concretos que determinem quando e como esses riscos se traduzirão em dano efetivo. Diante de tal lacuna, assumiu-se como hipótese para este presente artigo o fato de que a realização de grandes eventos contribui para o aumento dos registros de violações dos direitos de crianças e de adolescentes, sobretudo a exploração sexual.

Então, propõe-se, sem encerrar o assunto, produzir evidências que auxiliem os organizadores de grandes eventos, no futuro, a definirem estratégias concretas para a prevenção e o enfrentamento à exploração sexual contra crianças e adolescentes. As informações para essa reflexão foram extraídas do relatório Violação de direitos de crianças e 
adolescentes em grandes eventos esportivos - Copa do Mundo de Futebol 2014 (Childhood, 2017), do amplo apanhado de dados e informações que nele constam e, também, da necessidade de tecer algumas discussões conceituais sobre a exploração sexual, fazendo uma intersecção com os grandes eventos esportivos.

A pesquisa ora apresentada justifica-se por buscar maior entendimento a respeito da ocorrência desse tipo de violação de direitos no Brasil, considerando o período e os locais de ocorrência, perfil das vítimas e suspeitos. Iniciamos a discussão pela abordagem teóricoconceitual sobre eventos e a exploração sexual de crianças e adolescentes no contexto do turismo. A seguir, apresentamos a metodologia, de natureza quantitativa, para a seleção, sistematização e intepretação dos dados secundários. Ao final, são apresentadas as análises dos dados, traçando uma linha de tendência em busca de fatos ocorridos em grandes eventos e que possam ser identificados como padrão, destacando o período de realização da Copa do Mundo de Futebol, comparando, por exemplo aos carnavais. Ademais, identificamos as características da exploração sexual ocorrida no período. Por fim, destacamos as evidências possibilitadas a partir das análises.

\section{PERSPECTIVA CONCEITUAL}

A motivação para a realização de uma Copa do Mundo de Futebol é a oportunidade de mostrar as virtudes da nação ao mundo, principalmente pela extensa cobertura midiática dada ao evento, gerando exposição da localidade, do seu povo, da infraestrutura e atrações (Haynes, 1995; Ocke, 2013). Para além disso, os grandes eventos esportivos se transformaram em acontecimentos paradigmáticos, espetáculos midiáticos, com promessa de serem impulsionadores do desenvolvimento de cidades e das nações envolvidas em suas realizações (Aquino \& Ferrari, 2013). A publicidade, portanto, surge como um elo colonizador, pois, ao se apropriar do esporte e do turismo, fomenta mais um produto de consumo massivo a partir da união entre viagens e esportes.

Com o propósito de maximizar os resultados em ganho de imagem, os países receptores do campeonato de futebol elaboram projetos e canalizam investimentos abrangendo áreas como infraestrutura, integração regional, marketing, qualificação e serviços em prol da dinamização da atividade turística. Além disso, injetam no destino uma estrutura de oferta turística, com componentes interrelacionados e fortemente interdependentes (Raye, Souza, Viegas, \& Boaria, 2014). Pode-se afirmar que toda a rede turística da localidade onde ocorrem as competições, assim como os destinos com alta atratividade turísticas nessas imediações, são colocados à serviço do evento esportivo. Daí se conclui a natureza intrínseca 
entre grandes eventos esportivos e turismo.

Em torno da realização do evento, com toda a estrutura turística e arcabolso publicitário, cria-se um produto desejado no imaginário dos turistas de eventos. Estes, por sua vez, querem usufruir, da melhor maneira possível, a sua estada, sendo exigentes em termos de serviços. Para além de assistir as competições, os turistas demandam serviços de hospedagem, transporte, alimentação, serviços receptivos, visitas aos atrativos e outros não necessariamente relacionados diretamente ao turismo, assim como os novos produtos que são ofertados para melhor atendê-los. Isso contribui sobremaneira para a economia do destino, promovendo a ativação da cadeia produtiva do turismo (Firkowski, Baliski \& Ferreira, 2014; Cavalcanti \& Lima, 2013).

Diante da exposição da imagem do país, com atração de visitantes e mobilidade em território nacional, há a euforia do contato com novas culturas, costumes, saberes e fazeres, mas, também, o extravasamento que rompe os limites da liberdade individual, transgredindo normas sociais e, por vezes, os direitos humanos. Assim, a proteção às comunidades locais não pode ser negligenciada, já que a imagem que se quer promover pode se transformar em evidente problema, causando um efeito inverso, distanciando o público de interesse que se deseja conquistar. A má gestão do processo de organização e realização do evento, em geral de responsabilidade do setor público, pode certamente resultar em prejuízos econômicos e sociais relevantes ao país-sede, ao passo que uma gestão bem-sucedida pode oferecer ganhos substanciais à sociedade receptora do evento (Santos, 2017; Malhado \& Araújo, 2016; Diedrich; García-Buades, 2009).

Contraditória à expectativa da imagem positiva, no contexto das realizações de grandes eventos esportivos, há indícios de que estes podem aumentar a exposição de crianças e adolescentes aos diferentes tipos de violação de direitos, além de agravar suas condições socioeconômicas. De modo geral, conjectura-se (Rezende \& Barbosa, 2008; Brackenridge et al, 2013; Blerk \& Rizzini, 2015) um aumento nos riscos de exploração sexual de crianças e adolescentes e sobre quando e como esses riscos se traduzem em dano efetivo.

Portanto, há dubiedade em relação ao discurso sustentado, sobretudo por organizações internacionais, de que os eventos são impulsionadores de benefícios sociais, especificamente no que se refere à exposição de crianças e adolescentes às situações de abandono da sexualidade, de vulnerabilidades oriundas da pobreza, das discriminações de gênero, raça e geração, marcadas pela cultura da impunidade, muito comum em algumas regiões do mundo, principalmente naquelas com destacada desigualdade social, como é o caso do Brasil (Silva, 
2015).

Para Campos (2013) e Faleiros (2000), há em torno da exploração sexual uma rede de silêncio, conivência, omissão e impunidade, a qual é sustentada pelo lucro que se possa obter com o trabalho do corpo da criança ou do adolescente, na transformação e submissão destes em mercadoria humana para benefício sexual do cliente e benefício comercial dos proprietários do comércio e aliciadores. Quando visitantes nacionais ou internacionais, homens ou mulheres se beneficiam de "serviços" sexuais, estes ocorrem com a cumplicidade, por ação direta ou omissão, de agências de viagem, hotéis, transportes, bares, lanchonetes, restaurantes, barracas de praia, postos de gasolina, garçons, porteiros, caminhoneiros, taxistas, prostíbulos e casas de massagens, entre outros, além da tradicional cafetinagem.

$\mathrm{Na}$ medida em que o chamado turismo sexual é caracterizado como 'setor', propõe-se, portanto, uma ideia de institucionalização da exploração sexual como um espaço de investimento e arrecadação. Nesse sentido, Piscitelle (2010) ressalta que os termos, por exemplo, com os quais são descritos os 'paraísos naturais' brasileiros em notas sobre o ecoturismo, são, muitas vezes, os mesmos utilizados para descrever as 'morenas'. O chamado turismo sexual é, pois, divulgado pelo viés publicitário, como 'arena' na qual se intersectam movimentos de privatização da economia, construções imperiais de masculinidade e feminilidade, além de construções 'nacionais'; é quando a segmentação do mercado internacional de eventos se baseia na sexualização da terra e das pessoas, através da qual o destino é idealizado e projetado ao mundo como locus de prazer.

A visão setorizada do turismo sexual coaduna com a ideia do Brasil produto turístico e que tem sido construída nas últimas décadas, ou seja, desde que a imagem do país passou a estar atrelada à hipersexualização. Nas décadas de 1970 a 1990, a Empresa Brasileira de Turismo [Embratur] investiu na imagem, sobretudo, da mulher brasileira como atrativo, utilizando figuras femininas seminuas, associadas às paisagens naturais (como as praias) ou aos eventos culturais (como o Carnaval), institucionalizando no sentido do Brasil Turístico a imagem sexualizada dos brasileiros (Lopes \& Malerba, 2015). A unilateralidade que acaba levando à ligação direta, primeiramente, entre turismo sexual e exploração sexual de crianças e adolescentes, e, posteriormente, entre exploração sexual de crianças e adolescentes e situação de vulnerabilidade social, torna a análise causal simplista e dificulta a distinção entre segmento turístico e violações de direitos.

Silva (2015) e Silva e Avila (2010) abordam o turismo sexual como decorrente da falta de planejamento turístico, exclusão social, desemprego, falta de moradia, escolaridade, dentre outros aspectos. Portanto, não se trata de um segmento do turismo, mas 
fundamentalmente de uma relação de poder e de sexualidade mercantilizada, que visa à obtenção de proveitos por adultos e que causa danos bio-psico-sociais aos explorados, que são pessoas em processo de desenvolvimento. Por isso, é refutado pela área acadêmica do turismo não representá-lo do ponto de vista técnico, político e estrutural, nem mesmo corresponder aos princípios éticos do setor.

Procurando dar um pequeno contributo nesse sentido, Sacramento (2011) destaca a amplitude semântica incerta sobre o termo, já que é usado para traduzir diferentes cenários sociais e está associado a diferentes sentidos. É utilizado de modo amplo para se referir à circulação de pessoas, em viagens, e que tenham por base, ainda que não exclusivamente, motivações para relacionamentos afetivo-sexuais, heterossexuais ou homossexuais, de natureza comercial ou não, com residentes dos destinos turísticos.

Nas pesquisas nacionais, as reflexões não conduzem objetivamente à desmitificação do turismo sexual como um segmento, a fim de evidenciá-lo como uma prática que se utiliza do turismo para exercer uma atividade criminosa (Lei n. 12.015, 2009). Quando essa prática se adere ao tecido social local torna-se perniciosa, gera danos à sociedade e à imagem do destino turístico, levando à exploração sexual de crianças e adolescentes (Marques \& Mancini, 2014; Sobreira, Machado, Rebouças, \& Forte, 2014; Ferreira, 2008; 2011). Sua prática acirra problemas sociais, exacerbando a situação de pobreza, de violência doméstica intrafamiliar e extrafamiliar, e do uso de drogas, tornando crianças e adolescentes suscetíveis a todo tipo de exploração sexual, violência e trabalho infantil, conforme ressalta Gonçalves (2008).

Contudo, a desmitificação do termo turismo sexual, enquanto segmento, é banida pela sociedade civil ao ser cunhado por pesquisadores como exploração sexual no contexto do turismo (Childhood, 2017), definindo-o como grave violação dos direitos de crianças e adolescentes, portanto crime (Silva, 2015). A descaracterização do turismo sexual enquanto segmento é veemente notada nos documentos do governo federal brasileiro (MTur, 2013).

Por isso, mas não apenas, a exploração sexual de crianças e adolescentes em contextos de grandes eventos, sobretudo esportivos, requer um olhar sobre o mercado turístico brasileiro e suas nuances quanto aos tipos de turistas e atratividade dos destinos, com atenção redobrada aos impactos sobre a vida social das populações. Nesse âmbito, é estabelecido no Código de Ética Mundial do Turismo (Organização Mundial do Turismo [OMT], 1999), instituído pela Organização Mundial do Turismo (OMT) e ratificado pelos países membros, que o turismo, leia-se também setor de eventos, deve ocorrer nos territórios como instrumento de 
desenvolvimento pessoal e coletivo. As atividades devem respeitar a igualdade entre homens e mulheres, os direitos humanos devem ser promovidos e, em particular, os direitos específicos dos grupos de populações mais vulneráveis, especialmente as crianças.

Cabe aos gestores públicos, empresários, trabalhadores e comunidades dos destinos turísticos manter as crianças a salvo de qualquer situação de violação de direitos, em especial as sexuais. Entendido assim, de acordo com Leal (1998), do ponto de vista empírico, colocase a exploração sexual como um fenômeno que se apresenta em múltiplas e variadas situações, e que permite observar dimensões sociais, geográficas e cibernéticas. Portanto, não cabe se referir a esse fenômeno enquanto segmento turístico.

No Brasil, a garantia dos direitos de crianças e adolescentes adquiriu maior vulto e importância na agenda das políticas públicas a partir de 1990, com a promulgação do Estatuto da Criança e do Adolescentes - ECA, em consonância com a Convenção sobre os Direitos da Criança das Nações Unidas de 1989. Nessa direção, o Ministério do Turismo, na política de prevenção à exploração sexual, entre os anos 2005 e 2017, equiparou-se aos países como Colômbia e República Dominicana na adoção de códigos de conduta ou outras práticas responsáveis. A adoção desses códigos e práticas está em conformidade com os instrumentos da gestão pública: Política Nacional de Turismo (Lei n. 11.771, 2008), Plano Nacional de Turismo 2018-2023 e Plano Nacional de Enfrentamento à Violência Sexual Contra Crianças e Adolescentes 2013-2020 (Silva, 2015; Brackenridge et al, 2013; Gorenstein, 2008; Oliveira \& Zoauin, 2008).

Diante do delineamento político brasileiro, a partir dos anos 2000, as campanhas publicitárias voltadas ao público de turistas estrangeiros, com a finalidade de divulgar os atrativos do país e aumentar os fluxos turísticos, foram substancialmente alteradas, apresentando ao mundo uma outra perspectiva sobre o destino, pautada na diversidade étnica, cultural e natural, em oposição à imagem de um país de mulheres e jovens semi-nuas e sensuais (Instituto Brasileiro De Turismo [Embratur], 2009). Com esse enfoque, vários estudiosos (Campos, Tadioto, Bresolin \& Sangali, 2018; Bonfim \& Teles, 2017; Santos, 2017; Sobreira et al, 2014; Silva, Aragão \& Yamashita, 2015) têm investigado os benefícios e/ou os impactos dos grandes eventos no desenvolvimento do turismo nas comunidades-sedes. Nesses estudos, esse entendimento é ratificado pelo reconhecimento do potencial desses eventos, os quais estimulam mudanças na dimensão social e na forma como os principais agentes promovem (ou não) a garantia dos direitos de crianças e adolescentes. 


\section{PERSPECTIVA METODOLÓGICA}

Nos estudos sobre grandes eventos esportivos, em conexão com temas que passaram a ser observados como impactantes, dentre os quais a exploração sexual (Blerk \& Rizzini, 2015; Marquez \& Pinho, 2014; Brackenridge et al, 2013), é apontado, além da falta de ferramentas sólidas de monitoramento e avaliação das intervenções para a proteção à infância, a falta de evidências concretas sobre a existência de relação direta entre eventos esportivos e a violação de direitos contra crianças e adolescentes. A Childhood Brasil, em parceria com a Fundação OAK, a Universidade Católica de Brasília (UCB) e o apoio de consultores e de um Grupo Consultivo, formado por especialistas, representantes da sociedade civil, instituições públicas e organizações internacionais, iniciou, em 2015, pesquisa de coleta e organização dos principais dados referentes aos registros ${ }^{1}$ de diferentes violações dos direitos das crianças e adolescentes, especialmente a violência sexual antes, durante e depois da Copa do Mundo de 2014.

No estudo, os procedimentos metodológicos envolveram coleta e padronização das informações sobre o perfil das vítimas e dos autores, os tipos de violação e o local de ocorrência da violação de direitos. Essa coleta ocorreu entre janeiro de 2012 e dezembro de 2014, nas bases de dados dos Conselhos Tutelares (CTs) ${ }^{2}$, delegacias, unidades de saúde, Disque-Denúncia nacional e Disque-Denúncias locais. A pesquisa, desenvovida em sete etapas subsequentes, e, por vezes, concomitantemente, permitiu a identificação de 22 tipos de violências contra crianças e adolescentes. Contudo, para efeitos deste artigo, destacamos apenas os procedimentos e resultados para a violência sexual, notadamente a exploração sexual no contexto do grande evento esportivo. As etapas são as seguintes:

i. seleção das variáveis explicativas das violações e perfil dos envolvidos;

ii. padronização conceitual dos tipos de violação e subtipos, dos termos e das variáveis, considerando os diferentes bancos de $\operatorname{dados}^{3}$;

iii. concepção do instrumento de pesquisa;

\footnotetext{
${ }^{1}$ São considerados registros os fatos ocorridos que configuram ameaça ou violação de direitos de crianças e adolescentes, seja na forma escrita, por telefone, pessoalmente ou de alguma outra forma possível, registrados em formulário ou sistema específico. Não inclui os casos de atendimento ou encaminhamentos realizados.

${ }^{2}$ Em razão do limite de tempo e de recursos financeiros para esta pesquisa, o levantamento foi realizado apenas na cidade do Rio de Janeiro e em cinco Conselhos Tutelares, quatro localizados próximos aos espaços de acontecimento do Mundial e um distante.

${ }^{3}$ No Brasil, ainda não há um mecanismo de identificação de duplicidade de registros entre os bancos de dados, por isso, as análises são separadas.
} 
iv. validação da metodologia e dos instrumentos de pesquisa com a equipe e representantes do movimento nacional de proteção à infância;

v. concepção do banco de dados eletrônico, na plataforma eletrônica QuestionPro ${ }^{4}$, para inserção de dados, armazenamento e geração de relatórios preliminares;

vi. planejamento da pesquisa de campo, seleção e preparação da equipe, a qual é composta por 20 pesquisadores de campo, três pesquisadoras locais, dois pesquisadores seniores, um consultor na área da infância, um analista de dados sociais e uma estagiária;

vii. optou-se, como procedimento analítico, pela verificação do movimento apresentado através dos registros ao longo do tempo, ou seja, a tendência longitudinal entre 2012 e 2014, observando: a variação quantitativa e comparada dos registros por tipo de violação mais recorrente; a variação no período de grandes eventos - como carnavais e atenção especial à Copa do Mundo de 2014.

Considerando o tempo e os recursos limitados para uma ampla pesquisa em território brasileiro, optou-se pelo estudo de caso em três cidades: duas que foram sede da Copa do Mundo de Futebol de 2014 e que receberam o evento dos Jogos Olímpicos e Paraolímpicos Rio 2016, no caso, Rio e Janeiro (RJ) e Salvador (BA). A terceira não recebeu nenhum dos eventos esportivos, possibilitando um parâmetro de comparação - Belém (PA).

Faz-se importante registrar sobre o levantamento nos CTs. Tendo em vista a limitação de prazos e recursos financeiros para realizar a pesquisa, bem como a necessidade de conhecer informações de prontuários não digitalizados, foram selecionados cinco unidades na cidade do Rio de Janeiro, cinco localizados próximos às áreas de concentração de atrativos turísticos e, portanto, de maior movimentação de turistas em grandes eventos, e um localizado em área sem finalidade turística, mas com o maior número de registros no Disque-Denúncia local. Os resultados obtidos a partir desse levantamento foram analisados como estudo de caso e não foram tratados estatisticamente.

Por fim, optou-se como procedimento analítico a verificação do movimento apresentado pelos registros ao longo do tempo, ou seja, a tendência longitudinal nos anos de 2012, 2013 e 2014, tendo observado a variação quantitativa mensal dos registros; a variação no período de grandes eventos - atenção especial à Copa do Mundo de 2014 e este comparado a outros eventos, como o carnaval; e o perfil das vítimas e dos suspeitos.

\footnotetext{
${ }^{4}$ https://www.questionpro.com/pt-br/
} 


\section{EVIDÊNCIAS DA EXPLORAÇÃO SEXUAL EM CONTEXTO DE GRANDES}

\section{EVENTOS}

A exploração sexual no contexto do turismo é um tipo de violação de direitos contra crianças e adolescentes, representada na categoria Violência Sexual. No entanto, ainda verifica-se, especificamente no caso do Disque-Denúncia da cidade do Rio de Janeiro, o uso da nomenclatura prostituição infantil, há muito banida por remeter a criança ou o adolescente à condição permanente de responsável pela comercialização de seu corpo, destituindo-os de direitos. Por ser assim, é incoerente com o paradigma dos preceitos éticos e de responsabilidade social do setor turístico.

No período da análise, entre 2012 e 2014, observou-se como tendência a diminuição dos registros, comum a todas as cidades e a todos os bancos de dados, a exemplo da variação para todos os tipos de violação de direitos no banco de dados do Ministério da Saúde (Tabela 1). Todavia, nos meses que compreenderam a realização do mundial de futebol, junho e julho de 2014, a tendência verificada foi de aumento dos registros nos bancos de dados (exceto nos Disque-Denúncias locais), assim como foi em outros grandes eventos - carnaval (fevereiro de 2012 e 2013, março/2014).

Tabela 1 - Tendência dos registros de violência contra crianças e adolescetes no período da Copa do Mundo de futebol, entre janeiro de 2012 e dezembro 2014 (Variação)

\begin{tabular}{lrrr}
\hline Mês/Ano & Belém (PA) & Salvador (BA) & Rio de Janeiro (RJ) \\
\hline Carnaval Fev/12 & $-0,48$ & 0,10 & 0,19 \\
Carnaval Fev/13 & $-0,26$ & 0,15 & $-0,08$ \\
Carnaval Mar/14 & $-0,44$ & 0,26 & $-0,04$ \\
No período (2012-2014) & $-1,55$ & $-2,54$ & 0,28 \\
Ano - 2014 & $-0,54$ & $-2,00$ & $-0,60$ \\
Na Copa Jun-Jul/2014 & $\mathbf{- 0 , 3 4}$ & $\mathbf{- 0 , 4 1}$ & $\mathbf{0 , 1 4}$ \\
\hline
\end{tabular}

Fonte: Childhood Brasil, 2017. Banco de dados Sinan/Viva, Ministério da Saúde.

A comparação entre a cidade controle (Belém) e as cidades-sede do grande evento esportivo (Salvador e Rio de Janeiro) mostrou distinção, revelando que a variação não é determinada em função do evento, mas pelas características sociopolíticas da localidade, de acordo com a intensidade das intervenções da rede de proteção e condições de vulnerabilidade, nas quais estão submetidas crianças e adolescentes. Observou-se que o aumento no quantitativo de registros é fomentado em virtude das ações de prevenção articuladas entre todas as entidades membro do sistema de garantia de direitos, entre os quais figuram representantes de órgãos públicos nacionais e locais. Por conseguinte, a instalação de 
estruturas e os plantões de apoio em locais estratégicos inibiram o encaminhamento dos registros aos Disques-Denúncia locais.

É evidente o aumento de registros da violência sexual nos meses de realização da Copa (Tabela 1). Contudo, é denotada a subnotificação da exploração sexual e da exploração sexual no contexto do turismo (Tabela 2). Assim, mesmo quando há um registro de violação de direitos, este deve ser devidamente combatido.

Ao verificar os dados apresentados na Tabela 2, essa violação de direitos parece pouco significativa, com menor expressão.

Tabela 2 - Registros de violência sexual contra crianças e adolescetes no período da Copa do Mundo de futebol, junho e julho de 2014

\begin{tabular}{lrrr|rrr|rrr}
\hline & \multicolumn{3}{c}{ Belém $(\mathbf{P A})$} & \multicolumn{3}{c}{ Salvador $(\mathbf{B A})$} & \multicolumn{3}{c}{ Rio de Janeiro (RJ) } \\
\hline & \multicolumn{1}{c}{ VS } & ES & EST & \multicolumn{1}{c}{ VS } & ES & EST & VS & ES & EST \\
Viva/Sinan & 168 & 1 & --- & \multicolumn{1}{c}{51} & 0 & --- & 106 & 4 & --- \\
DD-100 & 66 & 15 & 0 & 155 & 30 & 0 & 196 & 50 & 2 \\
DD-Locais & 19 & 4 & --- & --- & --- & --- & 79 & 2 & --- \\
Delegacias & 53 & --- & --- & 67 & --- & --- & 285 & --- & --- \\
CT's-Rio & ---- & --- & --- & --- & --- & --- & 68 & 2 & 1 \\
\hline
\end{tabular}

Legenda: VS - Vioência Sexual ES - Exploração Sexual EST - Exploração Sexual no Contexto do Turismo '---' sem informação

Fonte: Childhood Brasil, 2017.

O DD-100 é o banco de dados com maior concentração de registros, tendo em vista as três cidades analisadas. Nos Disques-Denúncia locais das cidades do Rio Janeiro e Belém, a tendência foi de redução. $\mathrm{O}$ s registros nesses bancos de dados foram menores na copa do que na média anual. As delegacias de Salvador e do Rio de Janeiro apresentaram um aumento no quantitativo de registros; porém, em Belém diminuiu. Ressalta-se que, nesse último Banco de Dados, as informações foram agregadas por categorias e não por subviolações, pois as denominações, com base nos documentos jurídicos, nem sempre correspondem àquelas utilizadas na pesquisa. Qualquer intervenção incorreria em equívocos por não representar a realidade.

Durante o mundial de futebol foram registradas três ocorrências de exploração sexual no contexto do turismo: duas pelo DD-100 e uma pelo Conselho Tutelar da cidade do Rio de Janeiro. Esse fato ocorreu fora da área do fluxo turístico em razão da Copa do Mundo, data de junho de 2014, com criança (faixa etária de 0 a 11 anos) cursando a educação infantil, sobre a qual não se tem nenhuma outra informação. No entanto, no período do grande evento, não foi identificada alteração no perfil dos suspeitos e local de registro dos fatos. O ambiente 
intrafamiliar se mantém como contexto de ocorrência das violações, pois identificou-se que, entre os perfis suspeitos, estão pessoas do ambiente cotidiano das vítimas.

Como primeira evidência, constatamos que a exploração sexual, assim como a exploração sexual no contexto do turismo, são pouco expressivas nos bancos de dados e encontram-se quase inexistentes. A Copa do Mundo de 2014 pouco alterou a tendência dos registros feitos cotidianamente para esse tipo de violação. Essa tendência se justifica pelas ações dos comitês locais de proteção de crianças e adolescentes, que concentram os registros e atendimentos. Os registros notados por esses comitês integram relatórios não públicos, cujos dados não foram integrados aos bancos de dados oficiais e analisados no presente artigo. Portanto, há uma dissonância na gestão da informação durante a realização dos grandes eventos, a qual descontinua a alimentação dos bancos de dados oficiais, contribuindo para a invisibilidade da exploração sexual.

Também encontram-se justificativa nos esforços de toda a Rede de Proteção que, em convergência, desenvolveu estratégias de prevenção, coibindo as violações de direitos nas imediações dos espaços festivos. Como exemplo, tem-se a ação promovida na África do Sul, por ocasião da Copa do Mundo 2010, que reuniu esforços com a sociedade civil organizada, governos e organismos internacionais para coibir essa prática por turistas.

A ação na África do Sul resultou também na Red Card Campaign ${ }^{5}$, que treinou e capacitou cerca de 1000 agentes comunitários para identificar e prevenir a exploração sexual de crianças e adolescentes. Todo o esforço empreendido de forma cooperada entre as várias instituições e, em especial, o compromisso assumido pelos empresários do setor turístico, oportunizou a queda no número de registros e de vítimas. As ações na África do Sul foram concernentes às recomendações do ECPAT que, a partir de estudos de casos de turistas em viagem aos países com recorrentes denúncias de exploração sexual, recomendaram a realização de mais campanhas publicitárias, com vistas à sensibilização de toda a sociedade para os destinos onde há relatos de ação dos chamados “turistas sexuais" (Silva, 2015).

No Brasil foi organizada uma ampla agenda de proteção à criança e ao adolescente em grandes eventos, chamada de Agenda de Convergência, cujo objetivo é prevenir e intervir, em situações de ameaça e risco, os direitos humanos de crianças e adolescentes decorrentes da preparação e realização de grandes eventos. Liderada pela então Secretaria Nacional de Promoção dos Direitos da Criança e do Adolescente, a Agenda de Convergência foi resultado da articulação entre Ministérios, órgãos do sistema de justiça, organizações não

${ }^{5}$ Campanha Cartão Vermelho (tradução nossa). 
governamentais, comitês, fóruns nacionais, universidades, empresas e organismos internacionais. Uma das ações centrais foi a constituição de Comitês Locais de Proteção Integral nas 12 cidades-sede da Copa do Mundo. Esses comitês eram espaços de preparação das ações da rede, através da elaboração de um Plano Integrado de Proteção, de instituição de um plantão integrado, envolvendo equipes itinerantes, e de convivência.

A segunda evidência diz respeito aos novos contornos assumidos pela exploração sexual e pela exploração sexual no contexto do turismo, estabelecendo-se em diferentes espaços geográficos de eventos, bairros de classe média, nas comunidades de baixa renda e sob o domínio do tráfico de drogas. Por outro aspecto, as vítimas não se sentem exploradas, pois, a depender da situação e contexto, sentem-se lisonjeadas por terem sido escolhidas por homens mais velhos, traficantes e, talvez, turistas. Essa situação é tida por adolescentes - às vezes com a conivência de seus familiares - como um dos meios de obter benefícios financeiros e materiais (Gonçalves, 2008; Childhood, 2017). Ao sair do foco na vítima, aquela protegida pelos instrumentos legais da garantia dos direitos, o interesse recai sobre o pertencimento de crianças e adolescentes em situação de vulnerabilidade econômica e social no mercado de consumo.

É evidente que o aspecto da pobreza e da vulnerabilidade pertencem a contextos de risco para a exploração sexual, assim como coloca em discussão outros fatores que são invisibilizados nos bancos de dados quantitativos - o anseio por mobilidade social e o desejo pelo consumo de bens que não cabem no orçamento familiar de crianças e adolescentes (Marques \& Mancini, 2014; Ferreira, 2008).

Outro fato que contribui para a invisibilidade da exploração sexual, ao menos nos bancos de dados analisados, decorre do papel de intermediação assumido via redes sociais, o espaço cibernético, como sites de relacionamentos que contribuem para um agenciamento escondido. Observa-se que a alteração no modus operandi dos envolvidos nesse tipo de violência admite, nos tempos atuais, disfarces e subterfúgios. A subnotificação ainda é justificada diante da possível atuação estratégica das redes de exploração, que, por ocasião do aumento da visibilidade sobre esse tipo de violação de direito, alterna suas estratégias e se volta a outros espaços e tipos de organização.

É possível que os meios de comunicação, sobretudo as mídias sociais, influenciem as atitudes e costumes, e, dessa forma, atuem para favorecer a exploração sexual. Com isso, manifesta-se a permissividade da violação de direitos por turistas sobre os residentes (Ferreira, 2008). Em um contexto de convergência das mídias, de coexistência cybernética entre as pessoas, é preciso transcender os modelos de análise sobre consumo e recepção, 
típicos da cultura das massas. Portanto, precisamos ampliar nosso leque de métodos investigativos para além dos dados quantitativos, a fim de selecionar aspectos da cultura brasileira produzidos como espetáculo e apresentados como destaque, exaltando uma imagem que reforça estereótipos e mitos da sexualidade brasileira, além da imagem de Nação da impunidade.

Nesse sentido, Ferreira (2011) parece sugerir outro locus de investigação: o cyberespaço pode ser considerado uma extensão do mundo real, o local de encontro que propicia circulação fluida e articulações mais complexas entre pessoas de diferentes gêneros, localidades e classes socais. Logo, o cyberespaço pode se consubstanciar em um novo locus de ocorrência da exploração sexual. Todavia, a possibilidade de diminuição e, até mesmo, de inexistência dessa violação no período do grande evento não é descartada (Childhood, 2017).

A terceira evidência encontrada neste estudo refere-se à subnotificação e à falta de informação sobre os envolvidos e local de ocorrência dos fatos, as quais prevalecem em todos os bancos de dados, dificultando a caracterização dos indivíduos - vítimas e suspeitos. Credita-se essa falha à não percepção dessa violação por parte de profissionais e pesquisadores no decorrer do uso de formas tradicionais de identificação e controle, tornando imperceptíveis as condições pessoais e ambientais das vítimas. Urge, portanto, a necessidade de tornar mais consistentes os mecanismos de coleta, armazenamento, análise e divulgação desses dados - em prol da qualidade das informações e melhor descrição dos fatos; só assim será possível estabelecer medidas efetivas de monitoramento e de avaliação que nortearão as ações de prevenção em contexto de grandes eventos, desmitificando, ou não, o caráter dos eventos como propulsores da violação de direitos.

Tais fatos implicam o desenvolvimento de estratégias para padronização e uniformização interna das instituições e entre os órgãos que compõem o Sistema de Garantia de Direitos, sobretudo no que tange ao preenchimento de formulários, nível de informações e interpretação dos casos de exploração sexual.

A quarta evidência corresponde ao evento esportivo em território, que está à margem da visibilidade turística global e que impulsiona investimentos para a promoção de políticas locais, como as ações de prevenção à violação de direitos de crianças e adolescentes, notadamente as campanhas publicitárias que contribuíram para aumentar a quantidade de registros durante a Copa do Mundo de Futebol 2014. Em cenário realista, previsto por Sobreira, Machado, Rebouças e Forte (2014) para a cidade de Fortaleza, uma das cidadessede da Copa do Mundo de 2014, anteviu-se que o turismo local seria beneficiado pela 
realização do evento e que, com isso, as políticas públicas de combate à exploração sexual seriam fortalecidas. De fato, houve a intensificação das ações, dentre as quais a disponibilização de material e treinamento dos colaboradores do setor do turismo, medida já prevista na política de prevenção à exploração sexual do governo federal (MTur, 2013).Como quinta evidência, cabe destacar a consistência metodológica apoiada na técnica de análise de tendência, a qual se revelou simples, eficaz e com um instrumento de fácil replicação por gestores e pela sociedade civil. A metodologia aplicada constitui-se também como instrumento de monitoramento dos registros da exploração sexual em contextos de grandes eventos e no trato dos registros diários. Ademais, contribui para parametrizar as nomenclaturas nos diferentes bancos de dados, feito inédito no Brasil.

Por fim, a sexta e última evidência faz referência ao volume dos dados coletados e aos aprendizados conquistados durante a execução, constituindo um legado na área de proteção à infância no contexto do turismo de grandes eventos. No entanto, conforme comprovado nas evidências dois e três, o uso apenas da metodologia de cunho quantitativo, utilizada pelas instituições governamentais e da sociedade civil para gestão, não é suficiente para a compreensão da exploração sexual enquanto fenômeno. Outros métodos de pesquisas, notadamente os fenomenológicos, devem ser associados aos levantamentos no futuro.

\section{CONSIDERAÇÕES FINAIS}

O incentivo para produção do presente artigo partiu da hipótese de que a realização de grandes eventos contribui para o aumento dos registros de violação dos direitos de crianças e de adolescentes, especificamente a exploração sexual. Essa hipótese está confirmada. Nos resultados encontrados, concluímos que os tipos de violação registrados cotidianamente, e que ocorrem no âmbito intrafamiliar e comunitário, repetiram-se no período do grande evento, com aumento dos registros da exploração sexual. Contudo, evidencia-se que a exploração sexual e a exploração sexual no contexto do turismo constituem fenômenos invisibilizados.

Em complemento, o estudo favoreceu a identificação de outras cinco evidências que auxiliarão os organizadores de grandes eventos, no futuro, a definirem estratégias concretas para prevenção e enfrentamento da exploração sexual: os casos assumem novos contornos, se estabelecem em diferentes espaços geográficos, classes sociais e, também, sob o domínio do tráfico de drogas; a subnotificação e a falta de informação sobre os envolvidos e locais de ocorrência dos fatos dificultam a caracterização das vítimas e suspeitos; o evento impulsionou investimentos para a promoção de políticas de prevenção à violação de direitos de crianças e adolescentes; a consistência metodológica, apoiada na técnica de análise de tendência, se 
revelou simples e eficaz, além de um instrumento de fácil replicação por gestores e pela sociedade civil; e o volume dos dados coletados e os aprendizados constituem legado na área da proteção à infância no contexto do turismo de eventos.

No que tange ao aspecto conceitual e em contribuição ao pensamento do turismo enquanto ciência, sem a pretensão de encerrar o assunto, mas no intuito de fomentar a reflexão, as investigações apontam para o necessário rompimento com o discurso hegemônico do turismo sexual enquanto segmento. Em outra pespectiva, é preciso abordá-lo como prática que se apresenta em múltiplas e variadas situações, as quais são favoráveis à exploração sexual de crianças e adolescentes nas dimensões social, geográfica e cibernética. Os grandes eventos influenciam, positiva ou negativamente, nas condições de vulnerabilidades, as quais têm sua origem na pobreza, nas discriminações de gênero, raça e geração, marcadas pela cultura de impunidade, muito comuns em algumas regiões do mundo.

A coleta e a sistematização analítica dos dados contribuíram para revelar a dimensão ou o tamanho da incidência da exploração sexual de crianças e adolescentes no contexto dos grandes eventos esportivos. Nesse sentido, a presente pesquisa revelou-se como medida apurada, em termos quantitativos, para a produção de dados e evidências Os registros organizados em uma única base de dados e analisados de forma a se identificar a interferência do grande evento consistem como referência metodológica para futuros estudos quantiqualitativos, e em investigação sobre a correlação entre responsabilidade social dos destinos turísticos e a garantia de direitos.

Na perspectiva da gestão, a pesquisa produziu dados e evidências que podem auxiliar os organizadores de eventos dessa natureza a definirem estratégias concretas para a prevenção dessas violações. Além disso, há a possibilidade de se utilizar os resultados positivos, tratados neste estudo, como instrumento concreto de incentivo à efetivação da política de responsabilidade social no turismo e potencializar na publicidade internacional o destino Brasil. Nesse aspecto, é relevante destacar o êxito das ações, especialmente as campanhas publicitárias preventivas, que favorecem a gestão dos grandes eventos e ampliam os registros de violação de direitos.

Finalmente, propõe-se para o futuro investigar a relação entre imagem do destino Brasil e proteção à infância enquanto locus de turismo de eventos e construto para atração de outros eventos, a partir da verificação de animosidade dos turistas pelo produto Brasil. Adicionalmente, indica-se a continuidade da coleta sistemática de dados sobre exploração sexual de crianças e adolescentes, com foco de análise mantido em grandes eventos, como, 
por exemplo, a Copa Libertadores da América, o Campeonato Brasileiro etc., associados aos métodos de investigação fenomenológicos.

\section{REFERÊNCIAS}

Aquino, F., \& Ferrari, C. (2013). Gol de quem? A comunicação e o turismo na Copa do Mundo Brasil 2014. Revista Hospitalidade, São Paulo, X(1), 97-120.

Blerk, L., \& Rizzini, I. (2015). Let's Win This Game Together - Documenting violations of children's rights around the 2014 FIFA World Cup in Brazil. Universidade de Dundee.

Bonfim, I., \& Teles, M. (2017). Pós-Copa do Mundo de Futebol da FIFA no Brasil: legado (?) para o turismo esportivo. Turismo e Sociedade, 10(1), 1-21.

Brackenridge, C., Palmer-Felgate, S., Rhind, D., Hills, L., Kay, T., Tiivas, A., Faulkner, L., \& Lindsay, I. (2013). Child Exploitation and the FIFA World Cup: A review of risks and protective interventions. London: Brunel University.

Campos, N. (2013). Turismo, ética e responsabilidade social com crianças e adolescentes. Cenário, 1(1), 46-55.

Campos, L., Tadioto, M, Bresolin, A., \& Sangali, S. (2018). Brasil Turístico: efeitos de sentido e condições de produção na Copa do Mundo Fifa 2014, Brasil. Revista Rosa dos Ventos Turismo e Hospitalidade, 10(3), 623-635.

Cavalcanti, M., \& Lima, I. (2013). A hospitalidade urbana de Fortaleza-CE frente ao megaevento copa do mundo de 2014. Turismo: Estudos \& Práticas, 2(2), 107-132.

Childhood. (2017). Violação de direitos de crianças e adolescentes em grandes eventos esportivos - Copa do Mundo de Futebol 2014. Recuperado em 27, fevereiro, 2019 de https://www.childhood.org.br/fique-por-dentro\#publicacoes

Diedrich, A., \& García-Buades, E. (2009). Local perceptions of tourism as indicators of destination decline. Tourism Management, 30, 512-521.

Faleiros, E. (2000). Repensando os conceitos de violência, abuso e exploração sexual de crianças e adolescentes. Brasília: Thesaurus.

Ferreira, L. (2008). Turismo Sexual e a Comunicação - Um olhar hermenêutico sobre as relações entre visitantes e visitadas. Revista Brasileira de Pesquisa em Turismo, 2(2), 84-112.

Ferreira, L. R. (2011). Discurso, estereótipo e imaginário: a comunicação e o turismo sexual na convergência das mídias. Rosa dos Ventos-Turismo e Hospitalidade, 3(3), 324-336.

Firkowski, O, Baliski, P., \& Ferreira, A. (2014). Copa do Mundo no Brasil: entre expectativas elevadas e benefícios imprecisos. Turismo e Sociedade, 7(1), 41-63.

Gonçalves, L. S. (2008). Avaliação da Política Pública da Secretaria de Turismo de Fortaleza no Enfrentamento a Exploração Sexual de Crianças e Adolescentes. Dissertação de Mestrado em Políticas Públicas, Universidade Federal do Ceará, Fortaleza, Ceará, Brasil.

Gorenstein, F. (2008). A criação do Programa Turismo Sustentável \& Infância do Ministério do Turismo do Brasil: o desafio do enfrentamento à exploração sexual de crianças e 
adolescentes no turismo. Revista Acadêmica Observatório de Inovação do Turismo, 3(3), 112.

Haynes, R. (1995). The football imagination: the rise of football fanzine culture. Arena.

Instituto Brasileiro De Turismo - Embratur. (2009). Plano Aquarela 2020. Marketing Turístico Internacional do Brasil. Ministério do Turismo. Brasília.

Leal, M. (1998). A Exploração Sexual de Meninos e Meninas na América Latina e no Caribe. Relatório Final. Recuperado em 27, fevereiro, 2019, de https://docplayer.com.br/8569008-Aexploracao-sexual-comercial-de-meninos-meninas-e-adolescentes-na-america-latina-ecaribe.html

Lei n. 11.771, de 17 de setembro de 2008. (2008). Dispõe sobre a Política Nacional de Turismo, define as atribuições do Governo Federal no planejamento, desenvolvimento e estímulo ao setor turístico e revoga a Lei no 6.505, de 13 de dezembro de 1977. Brasília. Recuperado em 02, Agosto, 2019, de http://www.planalto.gov.br/ccivil_03/_Ato20072010/2008/Lei/L11771.htm

Lei n. 12.015, de 7 de agosto de 2009. (2009). Dispõe sobre os crimes hediondos, nos termos do inciso XLIII do art. 5o da Constituição Federal e revoga a Lei n-2.252, de 1o de julho de 1954, que trata de corrupção de menores. Brasília. Recuperado em 29, maio, 2019, de http://www.planalto.gov.br/ccivil_03/_Ato2007-2010/2009/Lei/L12015.htm\#art3

Lopes, A., \& Malerba, R. (2015). A imagem do Brasil como destino de turismo sexual na produção acadêmica de dissertações e teses (2001 - 2012). Caderno Virtual de Turismo, 15(2), 167-181.

Malhado, A., \& Araujo, L. (2016). Legados da Copa do Mundo: Como tornar realidade o legado de um megaevento para o desenvolvimento turístico sustentável?. Revista Iberoamericana de Turismo - RITUR, 6(2), 195-199.

Marques, N., \& Mancini, L. (2014). Turismo sexual: Carnaval, os prazeres da carne. Turismo e Sociedade, 7(2), 330-358.

Marquez, A., \& Pinho, J. (2014). Turismo e Exploração Sexual de Crianças e Adolescentes em Salvador, Bahia: o Estado, a sociedade e a realidade ignorada. Revista Turismo em Análise, 25(3), 552-579.

Melo Neto. F. (2001). Marketing de eventos. (3a. ed.). Rio de Janeiro: Sprint.

Ministério do Turismo. (2013). Manual do multiplicador - Projeto de prevenção à

exploraçãoo sexual de crianças e adolescentes no turismo. Brasília: Ministério do Turismo e Universidade de Brasília.

Ocke, M. (2013). Marca e imagem de um país: considerações sobre a Copa do Mundo 2014 e a promoção do Brasil. PODIUM: Sport, Leisure and Tourism Review, 2(2), 95-120.

Oliveira, C., \& Zouain, D. (2008). A responsabilidade social das empresas ligadas ao turismo em relação ao combate da exploração sexual de crianças e adolescentes. Revista Acadêmica Observatório de Inovação do Turismo, 3(3), 1-18.

Organização Mundial do Turismo - OMT. (1999). Código de Ética Mundial para o Turismo.. Recuperado em 10, setembro, 2013, de http://ethics.unwto.org/en/content/global-code-ethics- 
tourism.

Piscitelli, A. (2010). "Sexo tropical": Comentários sobre gênero e "raça" Em alguns textos da mídia brasileira. Cadernos pagu, 6(7) 9-33.

Raye, R., Souza, M., Viegas, L., \& Boaria, F. (2014). A Copa do Mundo 2014: Oportunidades e Prospecção geradas para a cadeia produtiva do turismo de Cuiabá MT. Revista de Turismo Contemporâneo, $1(1), 59.77$.

Rezende, C., \& Barbosa, L. (2008). Observatório de Inovação Social do Turismo: o envolvimento da academia, governo e sociedade civil organizada no combate à exploração sexual de crianças e adolescentes no turismo. Revista Acadêmica Observatório de Inovação do Turismo, 3(3), 1-14.

Sacramento, O. (2011). Homens em férias abaixo do equador: Questionando a sustentabilidade empírica do conceito de turismo sexual. Tourism \& Management Studies, (2), 1189-1192.

Santos, G. (2017). Diversidade de impactos econômicos da Copa do Mundo FIFA de 2014 no Brasil. CULTUR: Revista de Cultura e Turismo, 11(1), 202-219.

Silva, E. (2015). Turismo e a prevenção à exploração sexual de crianças e adolescentes no Brasil. In: Organizadores: Amorim, E., Soares, C., Tarlow, P. Segurança: um desafio para os setores de lazer, viagens e turismo. Portugal: Instituto Politécnico de Tomar/Escola Superior de Gestão de Tomar, 45-60.

Silva, E., Aragão, J. G., \& Yamashita, Y. (2015). Avaliando o legado de megaeventos esportivos: uma proposta conceitual e de mensuração. Revista Cenário, 4(7), 28-45.

Silva, T. A., \& Ávila, M. A. (2010). Turismo sexual e exploração sexual infantil: uma análise da atuação do programa sentinela em Ilhéus. Pasos, Revista de Turismo y Patrimonio Cultural, 8(1), 185-193.

Sobreira, M., Machado, C., Rebouças, C., \& Forte, S. (2014). Cenários Prospectivos no Combate ao Turismo Sexual Internacional em Fortaleza. Turismo-Visão e Ação, 16(2), 416449. 